\title{
Assessment of TC-Dominated Extreme Wind in the Scenario of Climate Change for Wind-Resistant Design of Super-Tall Buildings
}

\author{
$\mathrm{YC} \mathrm{He}{ }^{1}$ and $\mathrm{QS} \mathrm{Li}{ }^{2 *}$ \\ ${ }_{1}^{1} J o i n t$ Research Center for Engineering Structure Disaster Prevention and Control, Guangzhou University, Guangzhou, China \\ ${ }^{2}$ Department of Architecture and Civil Engineering, City University of Hong Kong, Hong Kong, China
}

*Corresponding author: QS Li, Department of Architecture and Civil Engineering, City University of Hong Kong, Hong Kong, China.

Received Date: March 02, 2020

Published Date: May 05, 2020

\section{Mini Review}

There is a fast development of super-tall buildings during the last decades especially in coastal regions where tropical cyclone (TC) may attack frequently. Owing to their high flexibility, these structures become considerably sensitive to wind, and windresistant performance has been involved as a critical aspect for the design, construction and maintenance of such civil structures. At TC-prone areas, information of TC wind offers a prerequisite for wind-resistant studies. Previous studies have shown that the greatest uncertainty source for wind-resistant design comes from inaccurate determination of wind information. Therefore, it is of great importance to quantify TC-wind characteristics as accurately as possible. However, wind-related items stipulated in many existing wind load codes/standards are established on the basis of wind measurements for non-TC events in the last century. Meanwhile, these items and many relevant studies account only for the lowest several hundred meters of the atmospheric-boundarylayer (ABL) whose depth has been increasing significantly above ever developing cities. Thus, they can hardly cater for the TCresistant design of super-tall buildings in the future whose heights should exceed one kilometer. Moreover, some detailed features of TC wind should be specially considered for the wind-resistant design of super-tall buildings, although they may be neglected acceptably for the cases of low-to-moderately-high buildings, such as the vertical variation of wind direction (also known as veering/ twisted wind) and air density. Results from field measurements demonstrate that within the ABL, the veering angle of TC wind can accumulate to $20^{\circ}-45^{\circ}$, and the air density may decrease along height by a factor of $\sim 10 \% \mathrm{He}$ et al. [1,2]. There is another important issue which has been rarely investigated in the field of wind engineering, i.e., climate-change effect on TC activities and TCdominated extreme wind. It is undoubted that the surface temperature of the earth gets warmer than ever before. Many meteorologists argue that the climate change has brought in and will continue to result in evident influence on TC activities (including the number of TC genesis, as well as the track and intensity of TC), although there are also some others who hold a cautious altitude $[3,4]$. It is noted that the extreme wind climate at many coastal areas is dominated by a number of strongest TCs that come across or get close to the studied sites. Hence, even if the climate change would trigger only a bit more severe TCs for a study site, the corresponding effects on associated extreme wind climate may become no table. In particular, super-tall buildings are extremely sensitive to wind action. Results from both field measurements and wind tunnel tests reveal that typical wind effects of super-tall buildings (e.g., wind-induced structural vibration) in general strength with the increase of wind speed exponentially, i.e., a small change in the design wind speed can result in a much larger variation of wind effects [6]. Apparently, there is a need to explore the effects of climate change on TCdominated extreme wind for the sake of the safety and serviceability of super-tall buildings in the future. There are two basic methods for assessing extreme-wind climate (or wind hazard): directly statistical analysis method, and Monte-Carlo sampling simulation (MCSS) approach. The former method requires long-term field measurements of wind climate be available, and assumes that the probability distributions of extreme wind follow certain statistical models (e.g., Wei bull distribution).Thus, the extreme-wind climate can be quantified through fitting the field measurements with an 
appropriate statistical model, from which the maximum wind speed associated with a required return period can be computed. However, because it is a low-probability event for TCs to attack a study site even at TC-prone areas, hundreds of or even thousands of years of wind climate measurements are needed to ensure the reliability of assessment results, which makes this method less applicable. To overcome the above problem, the MCSS approach has been proposed. The basic idea of this method lies in that one can simulate a sufficient number of $\mathrm{TC}^{\mathrm{s}}$ around the studied areas via a combined use of TC wind-field models and central-pressure filling models, as well as statistical models of the key parameters of TC. The TC-dominated extreme-wind climate can be then assessed based on the simulations of TC wind. Overall, the MCSS approach is regarded as a more effective method than the former, and related results have already been incorporated into some wind load codes (e.g., ASCE7 standard). Two specific techniques exist for the implementation of the MCSS method, which respectively focus on the site of interests (study-site oriented technique, hereafter) and the full track of a TC (TC-track oriented technique, hereafter). For the study-site oriented technique, an area centered at the study site should be pre-assigned (e.g., within $500 \mathrm{~km}$ distance from the study site). Key parameters to quantify the TCs within this area, including occurrence rate, center location, translational velocity, radius of maximum wind (RMW), Holland-B and central pressure, can be statistically modeled based on related historical records. A series of TC events that influence the study site can be then simulated via the Monte-Carlo sampling simulation method in conjunction with the above models. For each of these simulated TC event, one can generate the corresponding wind field by using a TC wind-field model. The TC-dominated extreme-wind climate can be finally estimated via the directly statistical analysis method. A typical limitation of the study-site oriented technique lies in that sufficient information of key parameters for $\mathrm{TC}^{\mathrm{s}}$ within the studied area should be available, which may not be satisfied for some cities. Meanwhile, as a site-specific method, it becomes inefficient for the case with a groups of cities. The TC-track oriented technique can be adopted to solve the above problems effectively [7,8].For this technique, the full track of a TC, from its generation to the dissipation, will be analyzed. Based on historical records, one can establish TC's genesis model and a series of recursive models for the

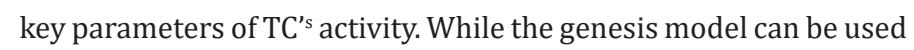
to predict the generation location and occurrence rate of TCs over the concerned ocean basin, the recursive models aim to generate synthetic tracks of TCs after their generation. Again, one can then simulate numerous $\mathrm{TC}^{\mathrm{s}}$ via the Monte-Carlo sampling simulation method, and generate the corresponding wind field above the studies sites for each of these TC events with the help of selected TC wind-field model. Due to its typical merits against the study-site oriented technique, the TC-track oriented technique as received increasing attention in the last decade. As stated above, $\mathrm{TC}^{\text {ss }}$ wind field model play an important role in assessing TC wind hazard. Basically, there are three kinds of wind field models in wind engineering: vertical profile model, slab model, and heightresolving model. The vertical wind profile, which is defined as the vertical distribution of wind speed, can be used to convert wind speed at a given point into the one at another height above a different terrain. The power-law and log-law are two widely utilized profile models, but both of them fail to account for the feature of low-level jet (LLJ) for TC wind whose heights (with a typical value equal to 500-1000 m) are observed to vary with storm-relative position and underlying surface [5].Continuous efforts have been made to develop more appropriate models for LLJ-featured TC wind profiles, such as the ones proposed by Vickery et al. [8] and Snaiki \& Wu [9]. The slab models Vickery et al [6] are based on the simplified Navier-Stokes Equation which accounts for the averaged horizontal wind field of a TC within the ABL. In practice, predictions via a slab model may be roughly regarded as TC gradient wind, and a vertical profile model can be further exploited to adjust the simulated gradient wind to those at other targeted heights. Heightresolving models have received more attention in recent years Snaiki \& Wu [10]. These models are able to reproduce the spatial distribution features of a TC, such as the storm-relative dependence of LLJ. A key issue involved in the height-resolving models is about the pressure-field model He et al. [11]. Conventionally, the heightdependence of TC pressure field is neglected, as only a shallow portion of the TC depth is considered. However, for the windresistance of super-tall buildings, such features should be taken into account as far as possible. The key parameters of TC activities also take an essential part in assessing TC wind hazard via the MCSS method. In fact, the effects of climate change on the assessment results are technically reflected by the relationship between longterm variation of global-temperature and such TC-activity parameters. In the scenario of climate change, the long-term evolutions of temperature should be first estimated possibly based on certain schemes of $\mathrm{CO}_{2}$ emission rate. Note that although in many studies climate change is regarded simply as the global warming at the Earth's surface, field studies have shown that atmospheric temperature at the tropopause has been decreasing at an even faster rate at the same time. According to the theory of TC's potential intensity (PI), the PI of a TC depends greatly upon the atmospheric temperatures at both the Earth's surface and the tropopause (i.e., the lower and upper boundary conditions of a TC). Thus, more efforts should be paid to a combined consideration of the atmospheric temperatures associated with the two boundary conditions. Based on the climate-change information, the long-term behaviors of TC genesis and TC track can be simulated via meteorological models. Recent studies reveal that the gridding size involved in the meteorological models can influence the prediction results significantly, and models with a too large gridding setup may not capture TC genesis sufficiently. Thus, downscaled gridding setups are suggested. The assessment of TC-dominated extreme wind for wind-resistant design of super-tall buildings involves many theoretical and technical issues, which should be analyzed systematically. It is stressed that TC activities possess distinct 
region-specific features, i.e., results of $\mathrm{TC}^{\mathrm{s}}$ obtained over one ocean basin may not be applicable for $\mathrm{TC}^{\mathrm{s}}$ over another Knutson et al. [4]. Thus, continuous efforts should be made to further understanding the TC-dominated extreme wind climate in different regions.

\section{Acknowledgement}

The work described in this paper was fully supported by a grant from the Research Grants Council of Hong Kong Special Administrative Region, China (Project No: CityU11207519) and grants from National Natural Science Foundation of China (Project No. 51978593, 51778554).

\section{Conflict of Interest}

No conflict of interest.

\section{References}

1. Li QS, He YC, He YH, Zhou K, Han XL (2018) Monitoring of wind effects of a landfall typhoon on a $600 \mathrm{~m}$ high skyscraper. Structure and Infrastructure Engineering 15: 54-71.

2. He YC, Li QS, Chan PW, Wu JR, Fu JY (2019a) toward modeling the spatial pressure field of tropical cyclones: insights from Typhoon Hato (1713). Journal of Wind Engineering and Industrial Aerodynamics 184: 378390.
3. Emanuel K (2005) Increasing destructiveness of tropical cyclones over the past 30 years. Nature 436(7051): 686-688.

4. Knutson TR, Mc Bride JL, Chan JJK, Coauthors (2010) Tropical cyclones and climate change. Nature Geoscience 3:157-163.

5. He YC, Chan PW, Li QS (2016) Observations of vertical wind profiles of tropical cyclones at coastal areas. Journal of Wind Engineering and Industrial Aerodynamics 152:1-14.

6. Vickery PJ, Skerlj PF, Twisdale LA (2000) Simulation of hurricane risk in the US using empirical track model. Journal of Structural Engineering 126: 1222-1237.

7. Chen Y, Duan Z (2017) A statistical dynamics track model of tropical cyclones for assessing typhoon wind hazard in the coast of southeast China. Journal of Wind Engineering and Industrial Aerodynamics 172: 325-340.

8. Vickery PJ, Wadhera D, Powell MD, Chen YZ (2009) A hurricane boundary layer and wind field model for use in engineering applications. Applied Meteorology and Climatology and Climatology 48: 381-405.

9. Snaiki R, Wu T (2018) A semi-empirical model for mean wind velocity profile of land falling hurricane boundary layers. Journal of Wind Engineering and Industrial Aerodynamics 180: 249-261.

10. Snaiki R, Wu T (2017) Modeling tropical cyclone boundary layer: heightresolving pressure and wind fields. Journal of Wind Engineering and Industrial Aerodynamics 170: 18-27.

11. He YC, Li YZ, Chan PW, Fu JY, Wu JR, et al. (2019b) A height resolving model for tropical cyclone pressure field. Journal of Wind Engineering and Industrial Aerodynamics 186: 84-93. 